\title{
Editorial
}

Pensar en Movimiento:

Revista de Ciencias del Ejercicio y la Salud ISSN 1659-4436

Vol. 10, No. 2, pp. 1-2

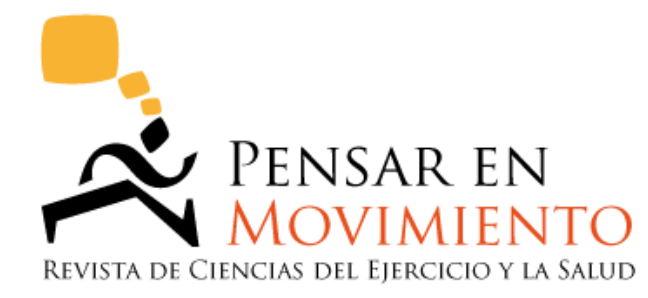

\section{LA MAGNITUD DE LO QUE SABEMOS VIS-À-VIS LO QUE NO SABEMOS}

En una conferencia que escuché recientemente por radio, el Dr. John Dickson, profesor de historia antigua de la Universidad de Macquarie en Australia, decía que la humildad tiene sentido porque lo que un experto o grupo de expertos sabe o puede hacer es básicamente nada, comparado con lo que no saben o no pueden hacer. Esa es una verdad contundente y chocante, particularmente a la luz de la suposición de que cuando uno realiza estudios de posgrado y obtiene una maestría en algún campo del saber, eso significa un dominio de todo el conocimiento que hay en ese campo en particular (cuando obtiene un doctorado va más allá pues aporta nuevo conocimiento a su campo y supuestamente demuestra su capacidad para seguirlo haciendo). En todo caso, ¿es necesario seguir aprendiendo? Si aceptamos la tesis del Dr. Dickson, ¡claro que sí!

Las revistas sujetas a revisión por pares cumplen un papel fundamental en la difusión y el avance del conocimiento. En ellas se publica lo más reciente después de un fuerte escrutinio de los revisores, esos pares académicos que hacen su labor en forma voluntaria como un servicio a la comunidad científica. Las personas que se dedican a la investigación saben que sus hallazgos no existen, más aún, no les pertenecen, sino hasta después de haber sido publicados. Además, todo lo que se ha publicado, está constantemente bajo la lupa de varias generaciones, las cuales lo ven con ojo crítico.

Algunos conocimientos están sujetos a ciclos, como es el caso de los métodos de entrenamiento que se ponen y pasan de moda y luego vuelven a ser popularizados por estrellas del entrenamiento personal (¿alguien dijo kettlebells?). También sucede con la forma en que nos habituamos a hacer las cosas, como he podido constatar ahora que cuento con el valioso aporte de nuestra nueva Editora, la Magistra Andrea Mora Campos: he tenido que ajustarme y reconsiderar algunas de las políticas de la revista cuando me ha presentado argumentos claros y sólidos, con la certeza de que esto redunda en beneficio para la revista. 
Sería sumamente satisfactorio para PENSAR EN MOVIMIENTO que los profesionales en Ciencias del Ejercicio cuestionaran sus propias prácticas o lo que ven hacer a otros, lo sometieran al estudio experimental y luego lo enviaran a consideración para publicación. $\mathrm{O}$ al menos que teorizaran sobre sus cuestionamientos y enviaran sus opiniones a nuestra sección Actualidades en Movimiento. De una u otra forma, la idea es contribuir a mantener viva la discusión sobre nuestro campo profesional, pues sabemos que lo que sabemos es nada, si se compara con lo que no sabemos aún. ¿Cierto?

Luis Fernando Aragón V., Ph. D., FACSM Director, Pensar en Movimiento Universidad de Costa Rica

\section{(ㄷ) (1)@}

